\title{
The Q-Switched Nd: YAG Laser in Tattoo Removal and the Effect of Lymphatic Elimination: An Experimental Study in Rabbits
}

\author{
S. Irkoren, C. Demirdover, B. Z. Akad, M. Gorgu \\ Adnan Menderes Universitesi, Tıp Fakültesi Plastik, ve Rekonstrüktif Cerrahi Anabilim Dalı \\ E-mail: saimeirkoren@hotmail.com
}

Received March 28, 2011; revised June 20, 2011; accepted June 30, 2011

\begin{abstract}
Background: Previously described methods for removal of tattoos are chemical, mechanical, surgical, termal and laser assited methods. Invention of the Q-switch mode, advanced the laser method, to be one of the most effective methods of tattoo removal. Objective: Comparing the tattoo removal and rate of lymphatic elimination of 3 different wavelengths of Q-switched Nd-YAG laser (532nm, 1064nm, combination $532+1064$ ). Methods: In this study we examined lymphatic elimination and the effect of $532 \mathrm{~nm}, 1064 \mathrm{~nm}$, and the combination $(532+1064 \mathrm{~nm}$ ) wavelength of laser pulse for the possible lymphatic cleansing mechanism of black pigmented tattoos. This study was performed on $18 \mathrm{New}$-Zealand rabbits, black pigmented tattoos were engraved on the back and the four extremities of the animals. $532 \mathrm{~nm}$ wavelength of Q switched Nd: YAG laser beam was applied on the left upper and bilateral lower extremities of the rabbits. During this period, excisional skin biopsies and lymph node biopsies were performed on days 7, 14 and 21. Results: Day 21 lymph node biopsies revealed mixed type of reactive hyperplasia and intracellular pigments were markedly seen in the laser treatment group and no intracellular tattoo pigment was seen in the control group. Conclusion: The findingd of this study indicate that lymphatic elimination may be one of the significant mechanisms of tattoo removal and the application of different wavelengths of Q-switched Nd-YAG laser do not show statistically significant differences in tattoo removal.
\end{abstract}

Keywords: Q-Switched Nd-YAG Laser, Tattoo Removal, Rabbits

\section{Introduction}

Traumatic and elective tattoo applications are widespread in the society. People, either due to psychosocial reasons or due to the constraint of society on them, want their tattoos removed for many reasons. Studies reveal that $42 \%$ of people apply to medical centers for the removal of their tattoos sometime during their lives [1].

Removing tattoos has gained wide practice among plastic surgeons. It is well known that pigment of tattoo can migrate to the regional lymph nodes [1,2]. The carbon particles mobilize and migrate through the lymphatics similar to melanoma cells and can be seen within the histiocytes or extracellularly. However, in this study we tried to show lymphatic elimination of the tattoo pigment occuring during late post-interventional periods when Q-switched Nd: YAG laser was utilized for treatment.

The aim of this study was to determine the timing of lymphatic elimination of tattoo pigment after laser treatment.

A variety of methods are used for removing tattoos such as chemical, mechanical, surgical, thermal and laser. However each method presents with its own advantages and disadvantages. "Selective photothermolysis" theory mentioned by Anderson and Parrish summarize that lasers only effect the pigment that are charged with wavelength specific chromophores [3-5].

Therefore, the dermis and dermal appendages, whereby the tattoo pigment lies, is protected so that the scar tissue does not form with this method. Several types of lasers such as Q- switched ruby laser, alexandrite laser and $\mathrm{Nd}$ : YAG lasers which can transfer large amounts of energy to the tissue in a matter of nanoseconds, are used in order to remove tattoos, [6,7]. The effect of these laser types is discussed in many studies but the "perfect tattoo laser" is not invented to date [8-10]. As black is the most com- 
monly used tattoo pigment, we used Q-switched Nd: YAG laser in different wavelengths including $532 \mathrm{~nm}$, $1064 \mathrm{~nm}$, and their combination $(532+1064 \mathrm{~nm})$ in our study. Many studies in the literature have shown the effectivity of lasers in tattoo removal. However, the mechanism of action remains an area that is not agreed. [11-13]. Studies have shown that lasers increase transepidermal migration by fragmenting the pigments with their photoacustic effects [14]. Also with their photothermal effects pigment are burned eventually causing fibrosis. [15]. In this study, the lymphatic elimination of tattoo pigment after the application of $532 \mathrm{~nm}, 1064 \mathrm{~nm}$ and $532+1064 \mathrm{~nm}$ wavelength of Q-switched Nd: YAG laser was investigated on black pigmented tattoos applied to $18 \mathrm{New}-Z$ Zealand rabbits.

\section{Materials and Method}

Albino, male 18 New Zealand rabbits weighing between 1500 - 2000 grams are utilized for this study. Animals were sedated with $1 \mathrm{mg} / \mathrm{kg}$ midazolam (Dormicum ${ }^{\circledR}$ ). The extremities were shaved and EMLA cream was applied for 1 hour before the tattooing process was initiated The tattoo gun, was a custom made 20 turns/second with 3 needles of $0.5 \mathrm{~cm}$ tips that has the ability to inject the pigment $1 \mathrm{~mm}$ deep into the dermis. The tattoo pigment was carbon based "Diamond Black" (CI 1253) and indian ink as a mixture. A total of 48 tattoos were applied on the extremities of the rabbits in a single session.

At the end of three weeks, laser treatment of different wavelengths (532 nm, $1064 \mathrm{~nm}$, and $532+1064 \mathrm{~nm})$ was applied to each animal and afterwards macroscopic and histopathological observations were made as designed.

Animal model: Tattoos were drawn on the four extremities of each rabbit. Right upper extremity of the animals were regarded as the control group. The left upper extremity and the bilateral lower extremities were selected as the experimental group. There were three experimental groups each including six rabbits (Table 1). Groups were identified as Group 532, Group 1064 and Group Combination (Scheme 1). Two passes of $532 \mathrm{~nm}$, $1064 \mathrm{~nm}$, and $(532$ + 1064) nm Q switched Nd: YAG laser was applied on the extremities of the animals with $450 \mathrm{~mJ}$ energy, 3mm spot diameter, $2 \mathrm{~Hz}$ frequency. Laser was applied to the extremities (Lightage, Q-Clear

Table 1. Design of experimental groups.

\begin{tabular}{lcccc}
\hline & Gr-532 & Gr-1064 & Gr-532 + 1064 & Gr-Control \\
\hline Day 7 & 6 & 6 & 6 & 6 \\
Day 14 & 6 & 6 & 6 & 6 \\
Day 21 & 6 & 6 & 6 & 6 \\
\hline
\end{tabular}
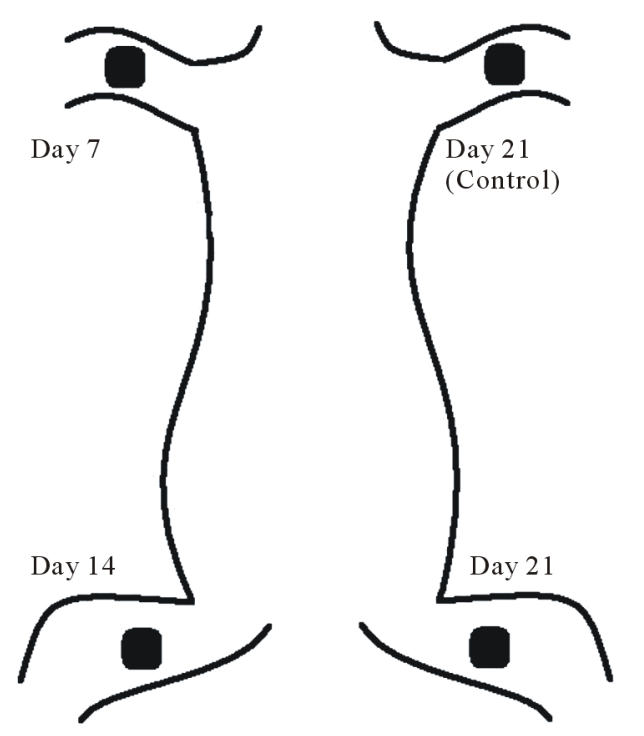

Scheme 1. Scheme representing the localization of lymph node biopsies taken from group 532, group 1064, and group combined (532 + 1064 nm).

$\left.{ }^{\circledR}\right)$ in a single session. Skin and lymph node biopsies were dissected on days 7, 14 and 21 (Figures 3-5). Axillary and inguinal node dissection with skin islands was performed as excisional biopsies. And Photographs were taken for macroscopic assessment (Figures 6, 7). Macroscopic assessment was made with Nikon Coolpix 5000 5.0 megapixel camera digitally in order to subjectively identify the amount of tattoo removal achieved with or without laser therapy. Photographs taken of the tattoos prior to and 6 weeks after treatment and were scored by three independent blind observers. Each observer was unaware of the study protocol and evaluated the tattoos on a clinical scale of $0-4(0=$ "no change", $1=$ " $1 \%$ $25 \%$ lightening, $3=$ " $51 \%-75 \%$ lightening and $4=$ " $76 \%$ - 99\% lightening”).

The animals were sacrified on the 21st day.

For histopathological assessment, microscopic slides were dyed with hematoxylene eosine and gomori trichrome dye and were examined under $20 \times, 40 \times$, and $100 \times$ light microscopic magnification .

\section{Results}

Control group, showed signs of fading over time, however no lymphatic cleansing of the tattoo pigment was noticed. This group was graded as " $0 \%-25 \%$ - poor removal of tattoos". All of the therapy groups showed cleansing of the tattoo pigments to various extent (Figures 1, 2). Clinical scale of all treatment groups (scale 3) were significantly better than the control group (scale 1). Histopathological examination revealed no significant difference between treatment groups ( $\mathrm{p}>0.05$ ). 
$A L$.

The results of microscopic examination for each group in various days is presented in Table 2.

Lymphoid hyperplasia in dissected nodes started to be detected on $14^{\text {th }}$ day. On $14^{\text {th }}$ day, lymphoid clearing was started in 4 animals in group 532-1064 and in 5 animals in group $532+1064$. On the $21^{\text {st }}$ day, lypmphoid clearance was detected in all animals in the treatment groups.

In no lymphatic clearence was detected in the control groups (Table 3 ).

\section{Discussion}

Laser removal of tattoos is based on the principle of selective absorption. The tattoo pigment, which is the.

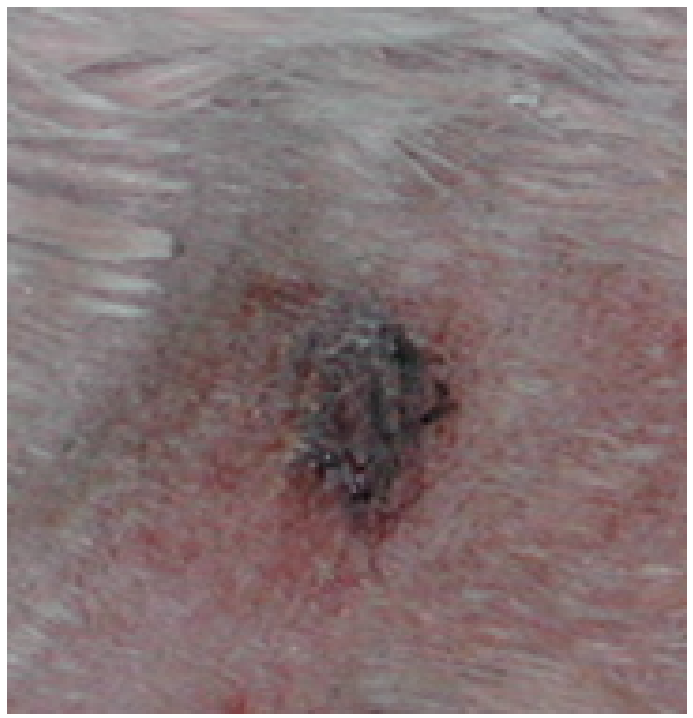

Figures 1. Macroscopic view of the tattoo on the extremity.

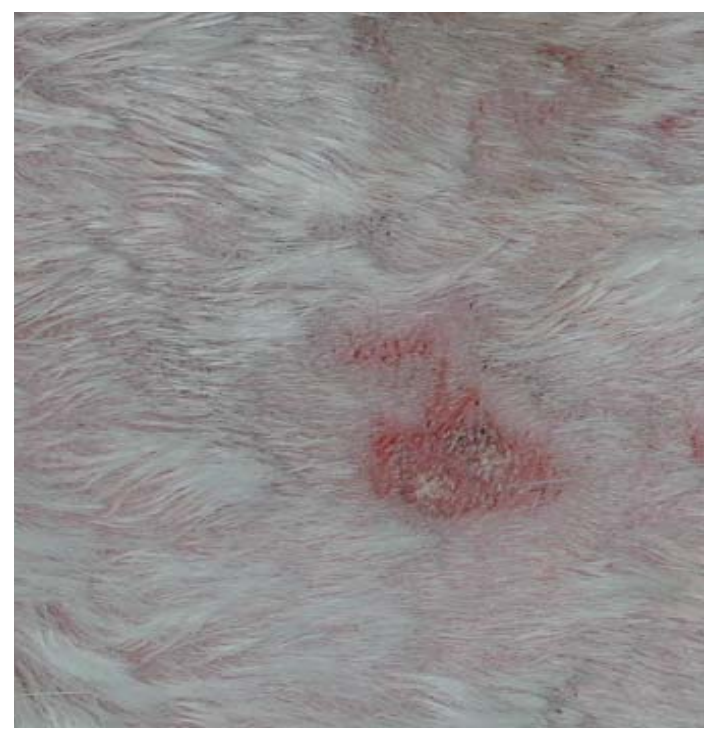

Figures 2. Macroscopic view of the cleansing after $532 \mathbf{~ n m}$ wavelength Q Switched Nd:YAG laser therapy.

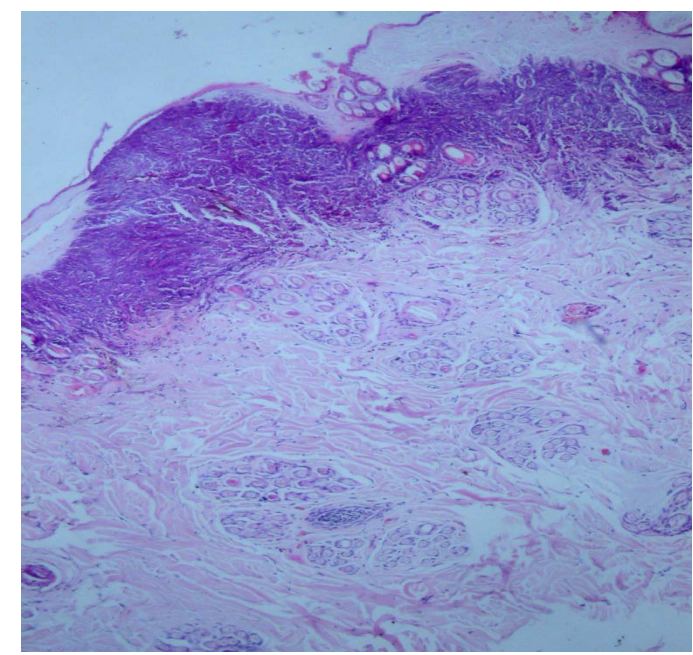

Figures 3. Post-laser seventh day skin biopsies stained in Haematoxylene-Eosine showing thermal necrosis and inflammatory cell reaction.

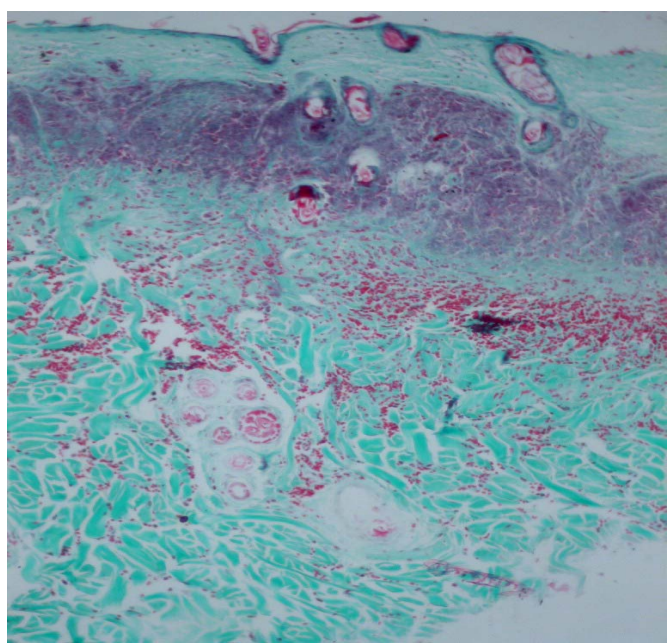

Figures 4. Post-laser seventh day skin biopsies stained in Gomori-Trichrome showing thermal necrosis and inflammatory cell reaction.

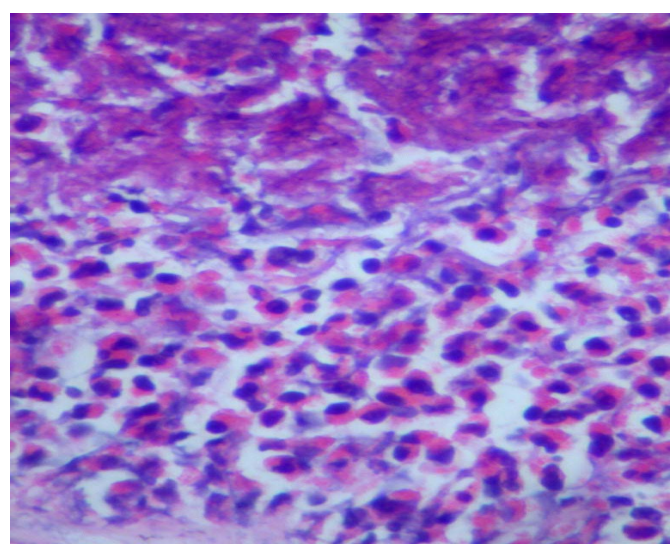

Figures 5. Post-laser $21^{\text {st }}$ day biopsies stained with Haematoxylene-Eosine $(\times 20)$ showingmixed type lymphoid reaction. 


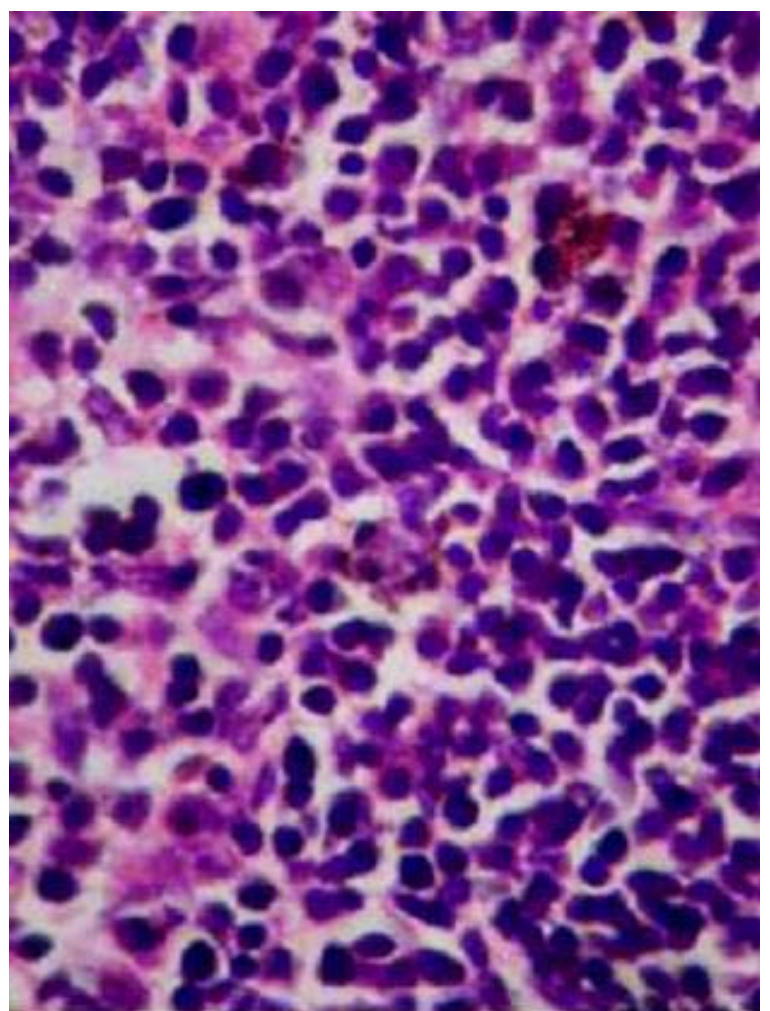

Figures 6. Intralymphatic view of tattoo pigments in Haematoxylene-Eosine $(\times 100)$.

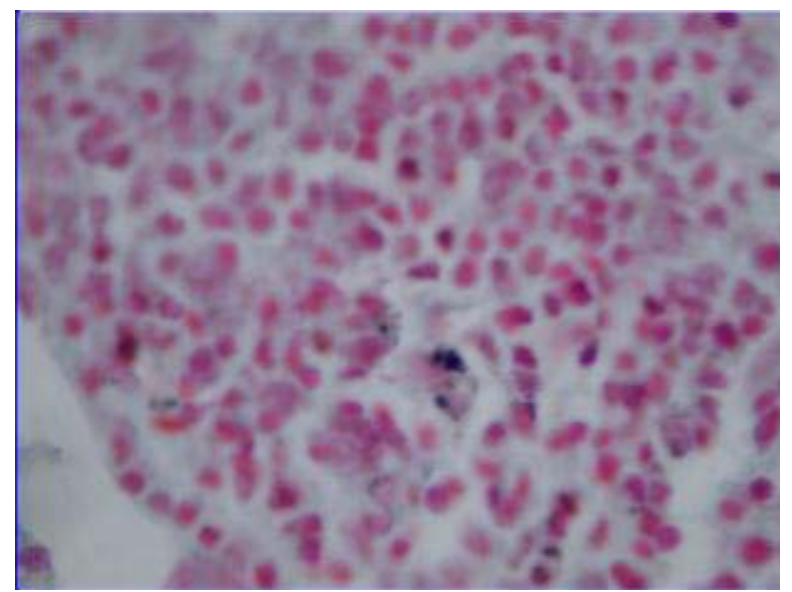

Figures 7. Intralymphatic view of tattoo pigments in Gomori Trichrome $(\times 100)$.

chromophore, absorbs the electromagnetic energy, the resultant thermaleffect being confined to the pigment The duration of exposure determines the extent of the local heating effect. The thermal relaxation time is the t1/2 time for tissue cooling and limiting exposure to less than this minimises the thermal effects on the surrounding tissues. This concept is one of the rationales for Qswitching a laser as it enables a high energy nanosecond duration pulse to be delivered. The bulk of tattoo

Table 2. Histopathological results comparing group-532, group-1064, group-532 + 1064, and group-control.

\begin{tabular}{|c|c|c|c|c|}
\hline & Gr-532 & Gr-1064 & Gr-532 + 1064 & Gr-Control \\
\hline Day 7 & $\begin{array}{l}\text { - } \\
\text { - } \\
\text { derusts of serous leakage } \\
\text { intact } \\
\text { Moderate inflammatory } \\
\text { reaction of macrophages } \\
\text { and leucocytes each } \\
\text { containing tattoo pigments }\end{array}$ & $\begin{array}{l}\text { - } \quad \text { crusts of serous leakage } \\
\text { - } \text { dermoepidermal junction } \\
\text { is intact } \\
\text { - } \\
\text { Moderate inflammatory } \\
\text { reaction of macrophages } \\
\text { and leucocytes each } \\
\text { containing tattoo pigments }\end{array}$ & $\begin{array}{l}\text { - } \quad \text { crusts of serous leakage } \\
\text { - } \text { dermoepidermal junction } \\
\text { is intact } \\
\text { - } \quad \text { Wide-spread inflammatory } \\
\text { reaction of macrophages } \\
\text { and leucocytes each } \\
\text { containing tattoo pigments }\end{array}$ & $\begin{array}{l}\text { - extracellular pigments } \\
\text { localized in the } \\
\text { superficial dermis }\end{array}$ \\
\hline Day 14 & $\begin{array}{l}\text { - moderate inflammatory } \\
\text { reaction in the dermis } \\
\text { intracellular pigment } \\
\text { localization (phagocytosed } \\
\text { by the macrophages. }\end{array}$ & $\begin{array}{l}\text { - } \quad \text { severe inflammatory } \\
\text { reaction in the dermis } \\
\text { - intracellular pigment } \\
\text { localization (phagocytosed } \\
\text { by the macrophages. }\end{array}$ & $\begin{array}{l}\text { - } \quad \text { severe inflammatory } \\
\text { reaction in the dermis } \\
\text { intracellular pigment } \\
\text { localization (phagocytosed } \\
\text { by the macrophages. }\end{array}$ & $\begin{array}{l}\text { - extracellular pigments } \\
\text { localized in the } \\
\text { superficial dermis } \\
\text { - } \\
\text { eosinophilically rich } \\
\text { dermis and mild } \\
\text { inflammatory reaction. }\end{array}$ \\
\hline Day 21 & $\begin{array}{l}\text { Gomori Trichrome dye } \\
\text { revealed no signs of } \\
\text { fibroblast increase nor } \\
\text { fibrosis formation } \\
\text { - In the histopathological } \\
\text { lymph node examination, } \\
\text { mixed type of reactive } \\
\text { hyperplasia and intracellular } \\
\text { pigments were seen }\end{array}$ & $\begin{array}{l}\text { Gomori Trichrome dye } \\
\text { revealed no signs of } \\
\text { fibroblast increase nor } \\
\text { fibrosis formation } \\
\text { - In the histopathological } \\
\text { lymph node examination, } \\
\text { mixed type of reactive } \\
\text { hyperplasia and } \\
\text { intracellular pigments were } \\
\text { seen }\end{array}$ & $\begin{array}{l}\text { - Gomori Trichrome dye } \\
\text { revealed no signs of } \\
\text { fibroblast increase nor } \\
\text { fibrosis formation } \\
\text { - In the histopathological } \\
\text { lymph node examination, } \\
\text { mixed type of reactive } \\
\text { hyperplasia and } \\
\text { intracellular pigments } \\
\text { were seen }\end{array}$ & $\begin{array}{l}\text { Pigments are } \\
\text { extracellularly localized } \\
\text { at the superficial dermis } \\
\text { - Gomori Trichrome dye } \\
\text { revealed no signs of } \\
\text { fibroblast increase nor } \\
\text { fibrosis formation } \\
\text { - In the histopathological } \\
\text { lymph node } \\
\text { examination, } \\
\text { intracellular pigments } \\
\text { were not seen }\end{array}$ \\
\hline
\end{tabular}


Table 3. Isolation of the tattoo pigments on lymph node biopsies.

\begin{tabular}{ccccc}
\hline & Gr-532 & Gr-1064 & Gr-532 + 1064 & Gr-Control \\
\hline Day 7 & 0 & 0 & 0 & 0 \\
Day 14 & 4 & 4 & 5 & 0 \\
Day 21 & 6 & 6 & 6 & 0 \\
\hline
\end{tabular}

pigment is found clumped within the dermis contained within fibroblasts and macrophages [3,25]. Following exposure, the production of $\mathrm{CO} 2$ and steam in the dermis forms vacuoles and causes the skin to whiten. This partly accounts for the disappearance of the pigment but also the pigment is disrupted into smaller particles allowing phagocytosis over the ensuing weeks. The frequency doubled Q-switched Nd: YAG laser (532 nm/1064 nm) is the most efficient laser for clearing red, brown, orange and black pigments $[3,8]$. As selective absorption by pigment is partly wavelength dependent [3,24]. Different kinds of ablative and nonablative lasers have been used for tattoo removal. After the innovation of Q-switched (QS) mode lasers, QS Nd: YAG, QS- Ruby, QS- Alexandrite lasers have been popularized in clinical use. Apart from the Q-switched mode Nd: YAG lasers, $\mathrm{CO}_{2}$ lasers and ablative lasers are also used for "difficult to remove" tattoos and tattoos composed of allergenic pigments. Q-switched mode Nd: YAG laser, transfer large amounts of energy to the epidermis in a matter of nanoseconds $[3,16]$. Tattoo clearing may occur via particle fragmantation, phagocytosis of cell death and subsequent elimination via lymphatics $[17,18]$. Selective photothemolysis theory popularized by Anderson and Parrish showed that Q-switch mode lasers show selective effects for pigment retaining cells. With this method, injury to the surrounding tissues is avoided by targeting only pigment including cells [19-21]. In this study; we evaluated lymphatic elimination with application of $532 \mathrm{~nm}, 1064$ $\mathrm{nm}$, and $(532+1064) \mathrm{nm}$ wavelengths of laser Also the timing and initiation of lymphatic elimination was tried to be established through serial biopsies.

Microscopically, laser therapy groups showed ondulation in dermoepidermal junction and epidermal pigment. containing keratinocytes. Studies in literature show that during the application of the tattoo pigment, trauma caused by the movements of the needle produce dermoepidermal lacerations leading to pigment leakage from this region which are then phagocytosed by keratinocytes and removed from the dermis [3,22]. This period lasts 7 - 10 days and ends when dermoepidermal unity is preserved again. This mechanism is named "transdermal migration" and is thought to be responsible for 30\% cleansing of the tattoo pigment. In our study this is the mechanism of tattoo fainting in the control group after 1 month. However in laser therapy groups, pigment in epidermal keratinocytes, increase laser's effect on transdermal migration. This may be due to basal membrane injury by direct effect, leading to disintegration of basal membrane cells by photoacustic effect and forming dermoepidermal tunnels by photothermal effect. However, electron microscopic studies are needed for further investigation.

Other dermal changes included thermal necrosis regions superficially and empty vacuoles around these necrotic regions. Pigments in laser therapy groups are found to be placed as small fragments around the vacuoles, partially phagocytosed by the macrophages. Literature review reveals that these vacuoles are formed due to the gas released after the thermal effect leading to inflammation reaction due to the photothermal affect [4]. These vacuoles are also hold responsible for the sudden paleness of the tissues right after the administration of the tattoo pigment. $\mathrm{CO}_{2}$ gas formed during the healing procedure of carbon based dye [5,13]. Small scattered fragment of pigments around the vacuoles are the results of high amounts of energy exploding due to the photoacustic effect of lasers according to our study. Vacuoles are found to disappear around day 7 and we believe that the mechanism for this is due to gas filled cavities are replaced by intertitial fluids. When comparing the control group with the laser therapy groups, the distribution of pigment in the dermis is one of the most striking differences. Previous studies revealed that photoacustic effect of laser cause the larger fragments to disintegrate and be easily phagocytosed by macrophagesThis may explain the faster removal of dermis in treatment group. [12]. Macrophages and polymorphonuclear leucocytes are much greater in number in laser therapy groups due to their role in effective phagocytosis and removal of the tattoo pigment. Some studies revealed that the tattoo pigment remain in the fibroblast in long-term periods [21]. In our study, none of the fibroblasts contained pigment in any of the biopsies however this may be interpreted as more time (more than 6 weeks) may be needed for that observation. Microscopic slides with Gomori Trichrome, revealed less fibrosis in the laser therapy groups, and this may be explained by selective injury of lasers to the pigment containing cells.

The effect of lymphatic system in tattoo removal is a subject discarded in many reports.

Some studies suggest a possible mechanism however, no experimental studies have been performed on this mechanism $[7,10]$. Tattoo is known to cause lymphadenopathy in the acute phase [2, 22]. This is thought to be due to local inflammation from the initial insult. However tattoo pigment in the lymph nodes after 3 months 
can not be described as acute inflammation. In our study we waited for 3 weeks for the acute inflammatory reaction to setle and then we applied the laser beam.

Our axillary and inguinal dissection results reveal a possible elimination via the lymphatic system starting from the 14 day post-laser treatment and makes a peak around 21 days post-laser treatment lymph node biopsies. Pigment that is fragmanted into small particles by laser therapy migrates to the dermis, where they are carried to the lymph nodes with protein enriched extracellular fluids. Pigment in the lymphoid sinuses are phagocytosed by macrophages and B,T cell lymphatics. This may initiate the allergic reaction to some types of tattoos by potentiating cellular and humoral immune responses [11].

The limitations of this study are several. First of all, although we are unable to control the application and type of pigment used in clinical practice. However, this study is limited to black carbon pigments. The lymphatic elimination may be further analyzed with other tattoo pigments than the carbon molecules in future studies. Secondly, in clinical practice we treat each tattoo 4- 12 times for maximum lightening and elimination. In this study, we evaluated the response after only a single dose of $532 \mathrm{~nm}, 1064 \mathrm{~nm}$ and combination $532+1064 \mathrm{~nm}$ wavelength Q-switched Nd: YAG laser treatment. We also noticed no statistically significant difference between the different wavelengths of lasers in changing the rate of lymphatic elimination.

\section{Conclusions}

As a result of this study we want to specifically emphasize that lymphatic elimination starts to guide laser tattoo treatment 14 days after a single application of $532 \mathrm{~nm}$, $1064 \mathrm{~nm}$ and combination 532 and $1064 \mathrm{~nm}$ wavelength Q-switched Nd: YAG laser treatment, with statistically significant difference on cleansing rate of the tattoo pigments, however further electron microsopic examination regarding the role of lymphatic elimination in long term results of laser treatment may be the inspiration for future experimental studies.

\section{Acknowledgements}

We would like to thank Laserium corporation for providing us the Lightage Q-Clear Laser. Their contribution is greatly valued.

\section{References}

[1] C. Jack, A. Adwani and H. Krishnan, “Tattoo Pigment in an Axillary Lymph Node Simulating Metastatic Malignant Melanoma," International Seminars In Surgical
Oncology, Vol. 1, No. 2, 2005, p. 28. doi:10.1186/1477-7800-2-28

[2] T. Friedman, M. Westreich, S. N. Mozes, A. Dorenbaum and O. Herman, "Tattoo Pigment in Lymph Nodes Mimicking Metastatic Malignant Melanoma," Plastic and Reconstructive Surgery, Vol. 111, No. 6, 2003, pp. 21202122. doi:10.1097/01.PRS.0000057101.95872.A1

[3] B. D. Zelickson, D. A. Mehregan, A. A. Zarrin, C. Coles, P. Hartwig, S. Olson and J. Leaf-Davis, "Clinical, Histologic and Ultrastructural Evaluation of Tattoos Treated with Three Laser Systems," Lasers in Surgery and Medicine, Vol. 15, No. 4, 1994, pp. 364-372. doi:10.1002/lsm.1900150406

[4] D. M. Ho, R. London, G. B. Zimmerman and D. A. Young, "Laser-Tattoo Removal-A Study of the Mechanism and the Optimal Treatment Strategy via Computer Simulations," Lasers in Surgery and Medicine, Vol. 30, No. 5, 2002, pp. 389-397. doi:10.1002/lsm.10065

[5] J. E. Ferguson, S. M. Andrew, C. J. P. Jones and P. J. August, "The Q Switched Neodymium: YAG Laser and Tattoos: A Microscopic Analysis of Laser-Tattoo Interactions,” British Journal of Dermatology, Vol. 137, No. 3, 1997, pp. 405-410. doi:10.1111/j.1365-2133.1997.tb03747.x

[6] M. L. Leuenberger, M. W. Mulas, T. R. Hata, M. P. Goldman, R. E. Fitzpatrick and J. M. Grevelink, “Comparison of the Q-Switched Alexandrite, Nd: YAG, and Ruby Lasers in Treating Blue Black Tattoos,” Dermatologic Surgery, Vol. 25, No. 1, 1999, pp. 10-14. doi:10.1046/j.1524-4725.1999.08122.X

[7] J. E. Ferguson and P. J. August, "Evaluation of the Nd: YAG Laser for Treatment of Amateur and Professional Tattoos,” British journal of dermatology, Vol. 135, No. 4, 1996, pp. 586-591. doi:10.1111/j.1365-2133.1996.tb03836.x

[8] S. L. Kilmer and R. R. Anderson, "Clinical use of the Q-Switched Ruby and the Q-Switched Nd: YAG( 1064 $\mathrm{nm}$ and $532 \mathrm{~nm}$ ) Lasers for Treatment of Tattoos,” Journal of Dermatologic Surgery \& Oncology, Vol. 19, No. 4, 1993, pp. 330-338.

[9] S. L. Kilmer, M. S. Lee, J. M. Grevelink, T. J. Flotte and R. R. Anderson, “The Q-Switched Nd: YAG Laser Effectively Treats Tattoos. A Controlled, Dose Response Study," Archives of Dermatology, Vol. 129, No. 8, 1993, pp. 971-978. doi:10.1001/archderm.129.8.971

[10] S. E. Dozier, D. G. Diven, D. Jones, et al., "The Q-Switched Alexandrite Laser's Effects on Tattoos in Guinea Pigs and Harvested Human Skin,” Dermatologic Surgery, Vol. 21, No. 3, 1995, pp. 237-240.

[11] R. O. Gregory, “Overview of Laser in Plastic Surgery,” Clinics in Plastic Surgery, Vol. 25, No. 1, 1998, pp. 6-10.

[12] R. O. Gregory, "Laser Physics and Physiology," Clinics in Plastic Surgery, Vol. 25, No. 1, 1998, pp. 89-93.

[13] E. V. Ross, S. Yashar, N. Michaud, R. Fitzpatrick, R. Geronemus, W. D. Tope and R. R. Anderson, "Tattoo Darkening and Nonresponse after Laser Treatment. A Possible Role for Titanium Dioxide,” Archives of Dermatology, Vol. 137, 2001, pp. 33-37. 
[14] B. E. DiBernardo and A. Cacciarelli, "Cutaneous Lasers," Clinics in Plastic Surgery, Vol. 32, No. 2, 2005, pp. 141150. doi:10.1016/j.cps.2004.11.008

[15] K. R. Suchin and S. S. Greenbaum, "Successful Treatment of a Cosmetic Tattoo Using a Combination of Lasers,” Dermatologic Surgery, Vol. 30, No. 1, 2004, pp. 105-107. doi:10.1111/j.1524-4725.2004.30024.x

[16] G. Jimenez, E. Weiss and J. M. Spencer, "Multiple Color Changes Following Laser Therapy of Cosmetic Tattoos," Dermatologic Surgery, Vol. 28, No. 2, 2002, pp. 177-179. doi:10.1046/j.1524-4725.2002.00161.x

[17] A. Jones, P. Roddey, I. Orengo and T. Rosen, "The Q-Switched ND: YAG Laser Effectively Treats Tattoos in Darkly Pigmented Skin,” Dermatologic Surgery, Vol. 22, 1996, pp. 990-1001.

[18] S. L. Kilmer, "Laser Treatment of Tattoos," Lasers in Dermatology, Vol. 15, No. 3, 1997, pp. 409-417.
[19] R. R. Anderson, “Regarding Tattoos,” Archives of Dermatology, Vol. 137, 2001, pp. 210-212.

[20] C. Gundogan, B. Greve, I. Hausser and C. Raulin, "Repigmentierung Persistierender Laserinduzierter Hypopigmentierungen Nach Tatowierungs-Entfernung Mit dem Excimerlaser," Hautarzt, Vol. 55, No. 6, 2004, pp. 549- 552. doi:10.1007/s00105-004-0718-3

[21] S. L. Kilmer, "Laser Eradication of Pigmented Lesions and Tattoos,” Dermatologic Clinics, Vol. 20, No. 1, 2002, pp. 37-53. doi:10.1016/S0733-8635(03)00057-3

[22] H. J. Zikrin, I. Avinoach and P. Edelwitz, "A Tattoo and Localized Lymphadenopathy: A Case Report,” Cutis, Vol. 67, 2001, pp. 471-472.

[23] T. Alster, "Q-Switched Alexandrite (755nm) Laser Treatment of Professional and Amateur Tatoos," Journal of the American Academy of Dermatology, Vol. 33, No. 1, 1995, pp. 69-73. doi:10.1016/0190-9622(95)90013-6 